\title{
Emissão de gases poluentes com a queima de casca de café
}

\author{
J. E. F. CIESLINSKI ${ }^{1}$, M. A. M. COSTA ${ }^{2}$, J. J. P. MELO ${ }^{3}$, F. A. FILHO \\ ${ }^{1}$ Professora Doutora - UNESP - Campus de Itapeva - Engenharia Industrial Madeireira \\ ${ }^{2}$ Professora Doutora - UNESP - Campus de Itapeva - Engenharia Industrial Madeireira \\ ${ }^{3}$ Assistente de suporte acadêmico - UNESP - Campus de Itapeva - Engenharia Industrial Madeireira \\ ${ }^{4}$ Assistente de suporte acadêmico - UNESP - Campus de Itapeva - Engenharia Industrial Madeireira \\ E-mail para contato: jefernandes@itapeva.unesp.br
}

\begin{abstract}
RESUMO - Uma das fontes energéticas que fornecem utilidade, flexibilidade, limpeza e economia é a biomassa. Entretanto, com a sua crescente oferta e utilização cresce também a preocupação das indústrias em investir no monitoramento e controle de suas emissões para a atmosfera, as quais muito contribuem para o desencadeamento de sérios problemas de saúde ao homem, além dos danos ambientais. Dentre as biomassas que podem ser utilizadas para fins energéticos está a casca de café que apresenta um poder calorífico próximo ao do carvão vegetal, é barata e ecologicamente correta. Além disso, durante o cultivo do café, muitas cascas de grãos são produzidas por ano no Brasil. Portanto, objetivou-se com este estudo monitorar as emissões de gases poluentes como monóxido de carbono $(\mathrm{CO})$, dióxido de carbono $\left(\mathrm{CO}_{2}\right)$ e óxidos de nitrogênio $\left(\mathrm{NO}_{\mathrm{x}}\right)$ produzidos durante a queima dessa casca. Os resultados mostraram que todas as emissões gasosas ultrapassaram os limites de emissão estabelecidos pelo CONAMA através das Resoluções CONAMA nº 03/90 (amostragem ambiental) e CONAMA n 382/06 (amostragem em dutos), sugerindo que haja um controle (limpeza) dos gases após a sua emissão e antes do seu encaminhamento à atmosfera. As maiores emissões de $\mathrm{CO}, \mathrm{CO}_{2}$ e $\mathrm{NO}_{\mathrm{x}}$ foram 3716 ppm, 1,8\% e 34 ppm, respectivamente. Observou-se, também, que as maiores emissões de $\mathrm{CO}$ ocorreram na fase de incandescência e as de $\mathrm{CO}_{2}$ e $\mathrm{NO}_{\mathrm{x}}$ na fase de chama.
\end{abstract}

\section{INTRODUÇÃO}

Os principais poluentes do ar provêm na sua maioria da queima de combustíveis para fins de transporte e produção industrial. Dentre os vários tipos de combustíveis disponíveis para consumo, recebe cada vez mais destaque a biomassa, como os resíduos agrícolas, os resíduos da indústria madeireira, entre outros, pois apresentam impactos ambientais muito menores que o uso de combustíveis fósseis.

O Brasil é um país que reúne inúmeras vantagens que o tornam capaz de atuar como líder no mercado mundial de produtos agrícolas, agroindustriais, silviculturais e, com isso, possui grande quantidade de biomassa energética na forma de resíduos dessas atividades. Segundo Webioenergias (2011), um desses resíduos é a casca de café, pois tem um potencial energético que pode, em alguns casos, torná-la substituta do carvão vegetal, sendo uma opção mais barata e ecologicamente correta para empresas que usam essa biomassa na geração de energia. 
Com a crescente oferta de biomassa como fonte de geração de energia nas diversas atividades industriais, cresce também a preocupação das indústrias em investir no monitoramento e controle de suas emissões para a atmosfera, pois durante a queima da biomassa são emitidos gases poluentes que muito contribuem para o desencadeamento de sérios problemas de saúde ao homem, além dos danos ambientais.

Neste contexto, este trabalho procurou caracterizar a casca de café e quantificar (amostrar) os poluentes gasosos emitidos a partir de sua queima para obtenção de energia.

\section{REVISÃO BIBLIOGRÁFICA}

A poluição atmosférica origina-se do aumento crescente da concentração de componentes indesejáveis na atmosfera, denominados poluentes atmosféricos, que podem afetar negativamente a saúde, a sobrevivência ou as atividades humanas e de outros organismos vivos.

\subsection{Poluentes atmosféricos}

Conceito: qualquer forma de matéria sólida, líquida ou gasosa e de energia que, presente na atmosfera, pode torná-la poluída.

Braga et. al. (2005) listam uma série de poluentes e suas fontes de geração:

- Óxidos de nitrogênio $\left(\mathrm{NO}_{\mathrm{x}}\right)$ : são produzidos em todos os processos de queima de combustíveis fósseis em contato com o ar. Além disso, também podem ser gerados nos processos de descargas elétricas na atmosfera;

- Óxidos de enxofre $\left(\mathrm{SO}_{\mathrm{x}}\right)$ : produzidos pela queima de combustíveis que contêm enxofre em sua estrutura, além de serem gerados em processos biogênicos;

- Monóxido de carbono (CO): gerado em processos de combustão incompleta de combustíveis fósseis e/ou outros materiais que possuem carbono em sua estrutura química.

Padrões de qualidade do ar: a determinação sistemática da qualidade do ar é limitada a um número pequeno de poluentes por serem de maior ocorrência e pelos efeitos adversos que causam ao meio ambiente.

No Brasil, o Conselho Nacional do Meio Ambiente (CONAMA), pela Resolução no 03/90, estabeleceu padrões nacionais de qualidade do ar (ar ambiente) e com relação aos limites de emissão para fontes fixas de geração de combustão, ou seja, para processos industriais de geração de calor, o Conselho Nacional do Meio Ambiente (CONAMA), através da Resolução no 382/06, estabeleceu padrões para o bagaço de cana-de-açúcar, que também podem ser considerados para a casca de café. 


\subsection{Biomassa}

Segundo Landim et al. (2001), a biomassa pode ser considerada como sendo toda a matéria orgânica capaz de, ao ser queimada, decomposta ou reciclada, gerar direta ou indiretamente, alguma forma de energia.

Fontes: Segundo Cortez, Lora e Gómez (2008), a biomassa pode ser obtida de vegetais lenhosos, como é o caso da madeira e seus resíduos de colheita (resíduos florestais) e de processamento (resíduos madeireiros) e de resíduos orgânicos, nos quais encontram-se os resíduos agrícolas (casca de café), urbanos e de animais. Assim como também se pode obter biomassa dos biofluidos, como os óleos vegetais (mamona, soja, etc.).

Caracterização: para poder determinar a potencialidade (eficiência) de uma biomassa como combustível, seu comportamento e compostos gerados durante a combustão deve se conhecer as suas características químicas e térmicas fundamentais. Essas características são a composição imediata (umidade, materiais voláteis, cinzas e carbono fixo) e poder calorífico (CORTEZ, LORA, GÓMEZ, 2008).

Processo de transformação da biomassa em energia (Combustão direta): método termoquímico no qual a biomassa é submetida a altas temperaturas na presença de oxigênio. É o método tradicional de produção de calor nos processos industriais. A descrição do processo de combustão pode ser feita através da classificação visual, quanto à existência ou não de chama, em três etapas: fase de ignição (apenas parte do combustível é tomada por chama intensa), fase de chama (pontos de chama em quase todo o combustível) e fase de incandescência (não há mais chama, ocorrendo a queima propriamente dita).

\subsection{Queima da biomassa - amostragem de gases}

A amostragem e o acondicionamento dos gases a serem analisados pode ser feita de forma contínua ou descontínua, através da extração de uma fração desses gases e direcionamento até o equipamento de análise ou diretamente no local (chaminé do queimador de biomassa) em processo de medição contínua (ALMEIDA FILHO, 2008).

\section{MATERIAIS E MÉTODOS}

\subsection{Materiais}

Foi utilizada a biomassa casca de café (Figura 1) adquirida de beneficiadora da região de Itapeva/SP. 


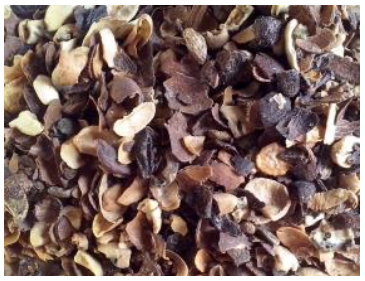

Figura 1 - Casca de café utilizada neste trabalho

\subsection{Métodos}

Caracterização da biomassa: a casca de café foi caracterizada através de análise química imediata (teores de umidade (U), materiais voláteis (MV), cinzas (CZ) e carbono fixo (CF)) com base na norma ASTM E-870-82 “Análise imediata para biomassa e resíduos" e através da determinação do seu poder calorífico superior (PCS) utilizando um sistema calorimétrico (calorímetro) demonstrado na Figura 2.

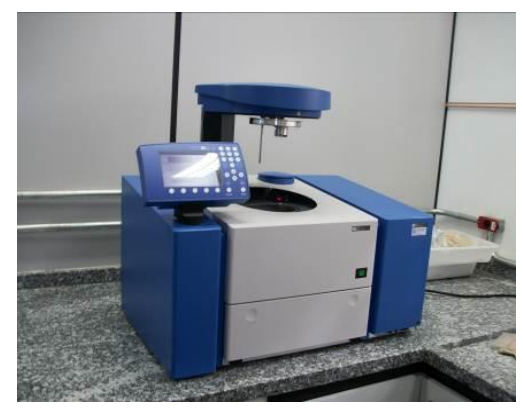

Figura 2 - Sistema calorimétrico (calorímetro)

Amostragem de gases: Para as queimas foi utilizado um sistema de queima de biomassa (Figura 3). O instrumento de amostragem foi o Unigás 3000+ da Eurotron Instruments (Figura 4). A sonda de amostragem foi inserida a aproximadamente 8 diâmetros internos à jusante e 2 diâmetros à montante dos distúrbios encontrados na chaminé do queimador de biomassa (Figura 5). 

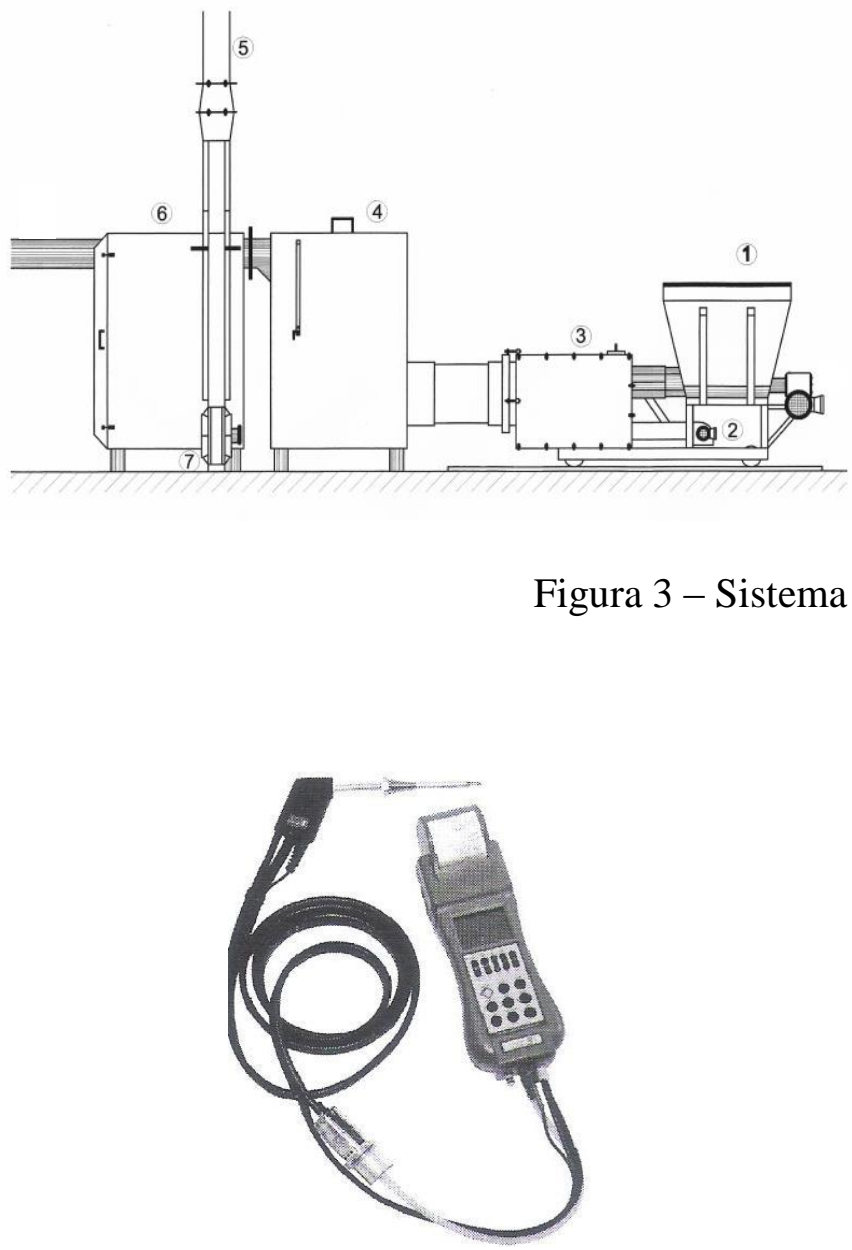

Figura 4 - Amostrador de gases
$1=$ alimentador de biomassa

$2=$ controlador de ar de alimentação

3 = queimador de biomassa

$4=$ trocador de calor

5 = chaminé

$6=$ estufa a ar quente

$7=$ soprador

Figura 3 - Sistema de queima de biomassa

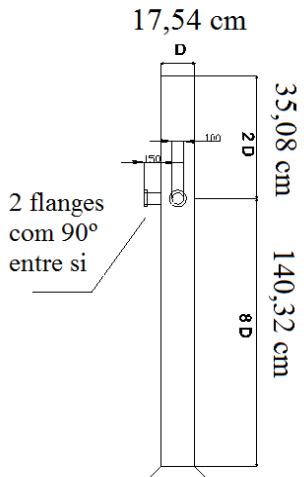

Figura 5 - Esquema da posição do orifício de amostragem na chaminé

\section{Resultados e Discussão}

\subsection{Caracterização da biomassa}

Os resultados obtidos neste trabalho foram comparados com os de Sánchez (2010) e encontramse nas Figuras 6 e 7. Tal comparação serviu como base de análise apenas, pois as amostras deveriam ser as mesmas (mesmo local de cultivo, mesmas espécies, etc.), o que não ocorreu. Entretanto, este fato descreve o que ocorre com a maioria das indústrias que queimam biomassa, ou seja, nem sempre as biomassas são adquiridas do mesmo local e com as mesmas características. 


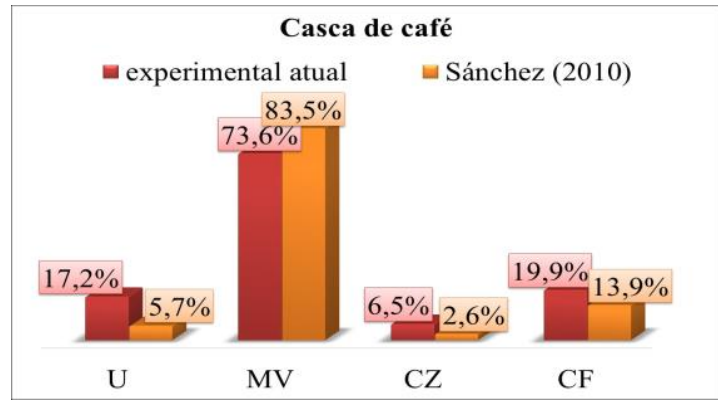

Figura 6 - Resultados de análise química imediata da casca de café

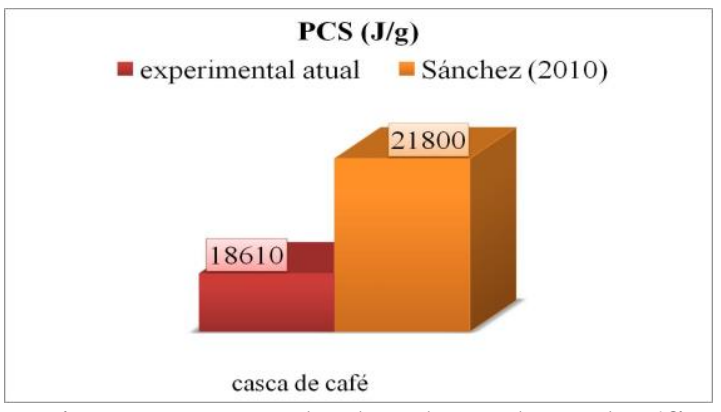

Figura 7 - Resultados de poder calorífico superior da casca de café

O teor de umidade influencia negativamente no poder calorífico de um combustível, o que pode ser verificado. A casca de café deste trabalho apresentou maior teor de umidade que Sánchez (2010) e consequentemente seu poder calorífico foi menor.

Com relação ao teor de materiais voláteis, quanto maior esse teor maior será a reatividade do combustível e mais fácil a sua ignição, além de resultar num maior valor de poder calorífico. Característica também observada para a comparação entre o experimental atual e o trabalho de Sánchez (2010).

Quanto ao teor de cinzas, resíduos resultantes da combustão dos componentes orgânicos e oxidações dos inorgânicos, o valor observado neste trabalho foi superior ao de Sánchez (2010) e o poder calorífico, por sua vez, resultou inferior, o que condiz com o mencionado por Rendeiro et al. (2008) e Klautau (2008) a respeito da alta concentração de cinzas diminuir o poder calorífico do combustível.

O teor de carbono fixo (medida indireta) foi inversamente proporcional ao poder calorífico, o que também era esperado segundo a literatura.

\subsection{Amostragem de gases}

As Figuras 8 à 10 mostram as concentrações de $\mathrm{CO}(\mathrm{ppm}), \mathrm{CO}_{2}(\%)$ e $\mathrm{NO}_{\mathrm{x}}(\mathrm{ppm})$ emitidos com a queima da casca de café. 


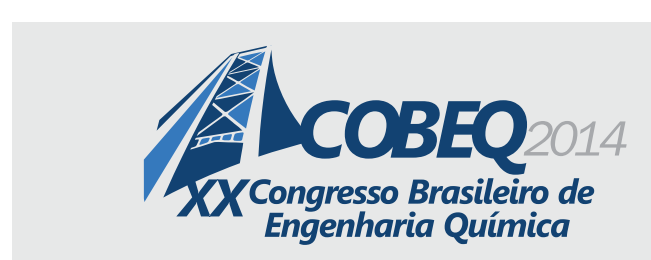

19 a 22 de outubro de 2014

Florianópolis/SC

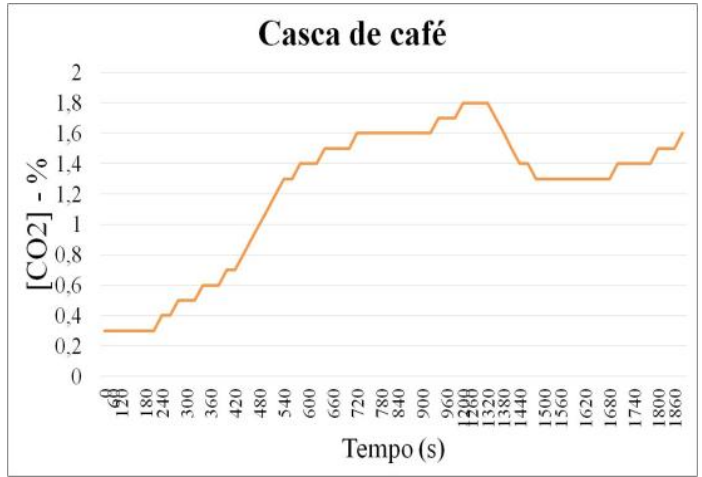

Figura 8 - Concentração de $\mathrm{CO}_{2}$ em função do tempo de queima da casca de café

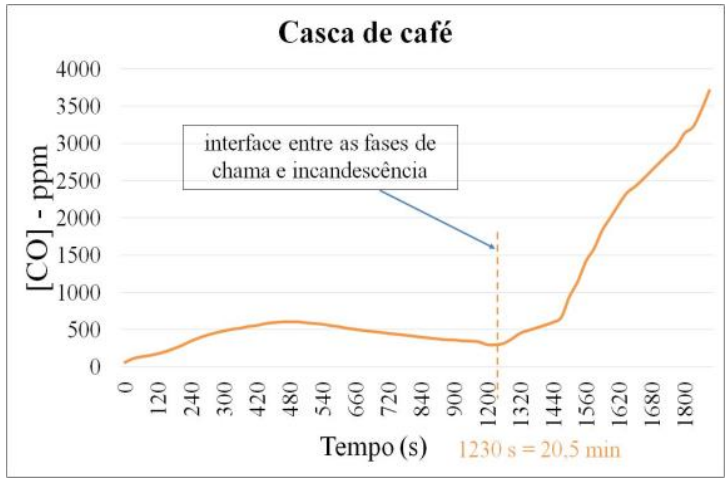

Figura 9 - Concentração de $\mathrm{CO}$ em função do tempo de queima da casca de café

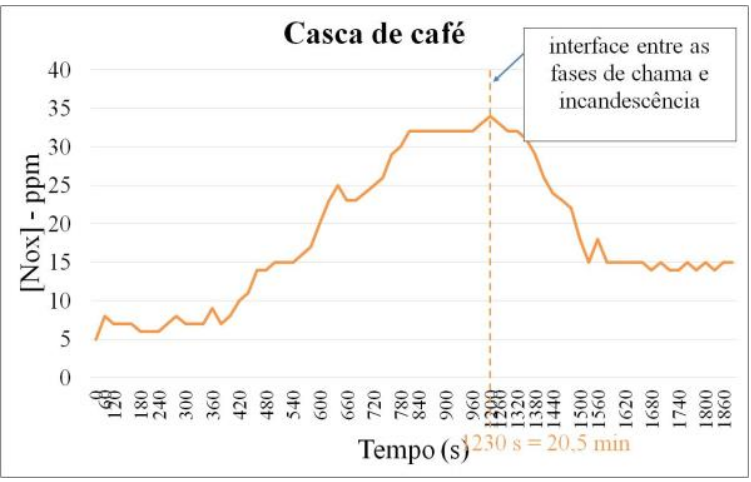

Figura 10 - Concentração de NOx em função do tempo de queima da casca de café

A partir da Figura 8 observa-se uma tendência de queda na concentração de $\mathrm{CO}_{2}$ na fase de incandescência (a partir de $1320 \mathrm{~s}$ ), comportamento semelhante observado por Soares Neto et al. (2011). As maiores concentrações de CO (Figura 9) foram observadas na fase de incandescência, assim como observado também por Soares Neto et al. (2011). A curva de concentração de CO para a casca de café revelou valores bem elevados, entretanto tais valores mostraram-se bem próximos aos alcançados por Limousy et al. (2013), que trabalharam com pellets de borra de café. As emissões de $\mathrm{NO}_{\mathrm{x}}$ diminuíram na fase de incandescência (curva decrescente na Figura 10), comportamento também verificado por Soares Neto et al. (2011), inclusive com intervalos de concentrações muito próximos nos dois estudos (5 - 34 ppm, presente estudo e 2 -24 ppm no de Soares Neto et al. (2011).

\section{REFERÊNCIAS}

ALMEIDA FILHO, F. Monitoramento e controle de emissão de material particulado em uma fonte estacionária. 2008. 131 f. Dissertação (Mestrado) - Programa de Pós-Graduação em Engenharia Química, Universidade Federal de São Carlos, São Carlos, 2008. 
BRAGA, B. et al. Introdução à Engenharia Ambiental: O desafio do desenvolvimento sustentável. São Paulo: Pearson / Prentice Hall, 2005.

CONAMA. Resolução Conama no 03/90:Padrões de qualidade do ar, previstos no PRONAR, 1990.

CONAMA. Resolução Conama $n^{\circ}$ 382/06: Limites máximos de emissão de poluentes atmosféricos para fontes fixas, 2006.

CORTEZ, L. A. B.; LORA, E. E. S.; GÓMEZ, E. O. (Org.). Biomassa para energia. Campinas: Editora da Unicamp, 2008. 736 p.

KLAUTAU, J. V. P. Análise experimental de uma fornalha a lenha de fluxo co-corrente para secagem de grãos. 2008. Dissertação (Mestrado) - Programa de Pós-Graduação em Engenharia de Recursos Hídricos e Ambiental, Universidade Federal do Paraná, Curitiba, 2008.

LIMOUSY, L. et al. Gaseous products and particulate matter emissions of biomass residential boiler fired with spent coffee grounds pellets. Fuel, v. 107, p.323-329, 2013.

RENDEIRO, G. et al. Caracterização energética da biomassa vegetal. Combustão e Gaseificação da Biomassa Sólida: Soluções energéticas para a Amazônia. Brasília: Ministério de Minas e Energia, $2008 . \quad$ p.52-63. Disponível em: <http://luzparatodos.mme.gov.br/luzparatodos/downloads/Solucoes_Energeticas_para_a_Amazonia_ Biomassa.pdf>. Acesso em: 15 mar. 2013.

SÁNCHEZ, C. G. (Org.). Tecnologia da gaseificação de biomassa. Campinas: Editora Átomo, 2010.

SOARES NETO, T. G. et al. Laboratory evaluation of Amazon forest biomass burning emissions. Atmospheric Environment, v. 45, p. 7455-7461, 2011.

WEBIOENERGIAS. Casca do café também é fonte de energia. Disponível em: $<$ http://www.webioenergias.com.br/noticias/biomassa/405/casca-de-cafe-substitui-carvaovegetal.html>. Acesso em: 05 jul. 2010. 